\title{
RANCANG BANGUN SISTEM INFORMASI AKADEMIK SISWA DENGAN MENGGUNAKAN NOTIFIKASI SMS PADA SMK MUHAMMADIYAH 1 KEPANJEN
}

\author{
Erwin Tidar Huda Utama ${ }^{1}$, Indra Dharma Wijaya ${ }^{2}$, Ariadi Retno Tri Hayati Ririd ${ }^{3}$ \\ Jurusan Teknik Elektro, Program Studi Teknik Informatika, Politeknik Negeri Malang \\ 1'tidarerwin@gmail.com, ${ }^{2}$ indra.dharma@gmail.com, ${ }^{3}$ faniri4education@yahoo.com
}

\begin{abstract}
Abstrak
Selama ini orangtua siswa sangat terbatas dalam memantau kegiatan akademik putra-putrinya disekolah. Apalagi untuk orang tua siswa yang sedang bekerja di luar kota sangat sulit untuk mendapatkan informasi akademik secara langsung dari pihak sekolah mulai dari prestasi, nilai ujian, hingga absensi putra-putrinya. Dengan demikian dibuatlah rancang bangun sistem informasi akademik siswa dengan menggunakan notifikasi SMS pada SMK Muhammadiyah 1 Kepanjen yang diharapakan mampu membantu orangtua siswa dalam memantau kegiatan belajar putra-putrinya disekolah, selain itu sistem ini dapat membantu para siswa agar terhindar dari teguran keras pihak sekolah karena absensi dan nilai akademik mereka yang menurun. Dengan adanya sistem informasi akademik siswa menggunakan notifikasi SMS ini akan lebih memudahkan para siswa mendapatkan informasi tentang nilai maupun absensinya di sekolah dan memudahkan orangtua siswa mendapatkan informasi nilai maupun absensi yang dikirim melalui SMS.
\end{abstract}

Kata Kunci : Sistem Informasi Akademik, Notifikasi SMS.

\section{Pendahuluan}

Perkembangan teknologi komputer sangat berperan dan membantu pekerjaan manusia dalam segala bidang sehingga menuntut manusia untuk memahami dan menguasainya guna mencapai tujuan yang dikehendakinya. Lembaga Pendidikan merupakan salah satu bidang vital yang memanfaatkan Teknologi Komputer. Tanpa teknologi komputer lembaga pendidikan dapat dikatakan belum cukup untuk mendukung proses belajar mengajar yang baik.

Permasalahan yang dihadapi SMK Muhammadiyah 1 Kepanjen adalah pengolahan data akademik yang masih manual dan tentunya sangat sulit untuk mendapatkan informasi tentang data akademik yang di inginkan, terutama untuk informasi nilai dan absensi siswa. Seharusnya orangtua siswa bisa mendapatkan informasi tentang nilai dan absensi siswanya agar dapat memantau prestasi akademik putra-putri mereka selama menempuh pendidikan. Untuk mengatasi permasalahan ini maka akan di rancang dan di bangun sistem informasi akademik siswa dengan notifikasi SMS yang mampu meberitahukan data nilai dan absensi kepada siswa dalam bentuk website, serta memberitahukan data nilai dan data absensi dalam bentuk SMS kepada orang tua siswa.

Disamping memudahkan siswa melihat data nilai dan data absensi, sistem ini juga di lakukan untuk meningkatkan kedisiplinan terhadap siswa karena didalam sistem ini melibatkan orang tua untuk notifikasinya. Sebelumnya pada sistem absensi yang diterapkan sekolah adalah dengan menggunakan surat, jadi ketika siswa tidak mengikuti pelajaran tanpa keterangan maka sekolah akan mengirim surat kepada orang tua siswa. Pengiriman surat akan dikenakan biaya dengan waktu pengiriman maksimal dua hari. Kemudian untuk sistem nilai ujian pada sekolah ini masih menggunakan pengarsipan kedalam buku raport, jadi ketika siswa ingin melihat nilai ujian maka siswa harus menanyakan kepada bagian admin, setelah itu admin mencarikan buku raport atau nilai ujian siswa. Maka dengan memanfaatkan sistem notifikasi SMS ini admin dapat memboadcast pesan kepada seluruh wali murid bahwa nilai dan absensi siswa dapat di akses melalui request SMS dengan format penulisan SMS yang sudah ditetapkan, sistem juga dapat mengirim pesan ototmatis kepada orangtua jika absensi 
siswanya melebihi batas pelanggaran, selain itu untuk siswa juga dapat melihat indformasi data nilai dan absensinya melalui website.

Dengan adanya sistem ini maka para siswa tidak susah-susah lagi mencari berkas yang begitu banyak untuk mengetahui data akademiknya, selain itu bagi para orangtua siswa pengawasan siswa lebih mudah, karena orangtua dapat mengetahui data nilai dan absensi anaknya melalui SMS. Dilihat dari kenyataan tersebut, diperlukan suatu sarana penunjang yang mampu meningkatkan efektifitas dan efisiensi pengolahan data akademik yang ada di SMK Muhammadiyah 1 Kepanjen. Sarana ini dibuat dengan berbasis web sehingga dapat digunakan dengan baik di lingkungan sekolah. Oleh karena itu, penulis berpikir untuk merancang dan membangun suatu sarana penunjang pendidikan dengan judul "Rancang Bangun Sistem Informasi Akademik Siswa Dengan Menggunakan Notifikasi SMS Pada SMK Muhammadiyah 1 Kepanjen".

\section{Teori Dasar}

A. SMS Gateway

1. Short Message Servive (SMS)

SMS adalah teknologi yang memungkinkan untuk menerima maupun mengirim pesan antar telepon bergerak (ponsel). Teknologi ini pertama kali diperkenalkan pada tahun 1992 di Eropa oleh ETSI (European Telecommunications Standart Institute), dan pada awalnya menjadi suatu standar untuk telepon wireless yang berbasis GSM (Global System for Mobile Communications). Namun, teknologi lain sperti CDMA dan TDMA pun memasukkan SMS sebagai fitur standar.

Sesuai dangan namanya, SMS yang berarti layanan pendek, maka besar data yang ditampung oleh SMS sangatlah terbatas. Untuk satu SMS yang dikirimkan, hanya dapat menampung paling banyak sebesar 140 byte atau sekitar 1120 bites. Bila diubah kedalam bentuk karakter, maka untuk satu SMS hanya dapat berisi paling banyak 160 karakter untuk karakter latin, 70 untuk karakter non-latin seperti Cina maupuun Jepang.

2. SMS Gateway

Istilah gateway, bila dilihat pada kamus Inggris-Indonesia diartikan sebagai pintu gerbang. Namun pada dunia komputer, gateway dapat berarti juga sebagai jembatan penghubung antar satu sistem dengan sistem lain yang berbeda, sehingga dapat terjadi suatu pertukaran data antar sistem tersebut. Dengan demikian, SMS gateway dapat diartikan sebagai suatu penghubung untuk lintas data SMS, baik yang dikrimkan maupun yang diterima.

Seiring perkembangan teknologi komputer, baik dari sisi hardware maupun software, dan perkembangan teknologi komunikasi, SMS gateway tidak lagi dimaksudkan sebagai ilustrasi diatas. Masayarakat lebih menagartikan SMS gateway sebagai jembatan komunikasi yang menghubungkan perangkat komunikasi (dalam hal ini ponsel) dengan perangkat komputer yang menjadikan aktifitas SMS lebih mudah dan menyenangkan. Pengertian SMS gateway kemudian lebih mengarah pada sebuah program yang mengkomunikasikan antara sistem operasi komputer, dengan perangkat komunikasi yang terpasang untuk mengirim atau menerima SMS. (Pramono, 2010).

3. Cara Kerja SMS Gateway

Dalam sistem SMS, mekanisme utama yang dilakukan dalam suatu sistem adalah melakukan pengiriman short message dari satu terminal customer ke terminal yang lain. Hal ini dapat dilakukan berkat adanya sebuah entitas dalam sistem SMS yang bernama Short Message Service Center (SMSC), disebut juga Message Center (MC). Pada saat pesan SMS dikirim dari handphone (mobile orginated) pesan tersebut tidak langsung dikirim ke handphone tujuan (mobile terminated), akan tetapi terlebih dahulu ke SMSC, baru kemudian pesan tersebut dikirimkan ke handphone tujuan.

SMSC merupakan sebuah perangkat yang melakukan tugas store and forward trafik short message. Di dalamnya termasuk penentuan atau pencarian rute tujuan akhir dari short message. Sebuah SMSC biasanya didesain untuk dapat menangani short message dari berbagai sumber seperti Voice Mail System (VMS), Web-based messaging, Email Integration, External Short Message Entities (ESME), dan lain-lain. (Wiharto, 2011)

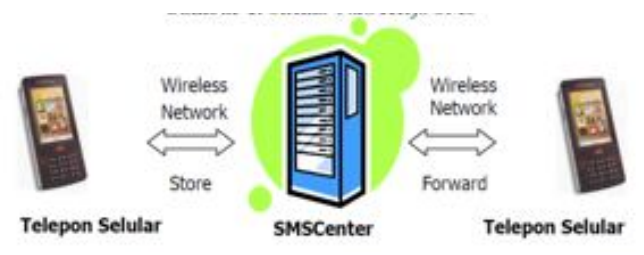

Gambar 1. Skema Cara Kerja SMS Gateway

\section{B. Gammu}

Gammu adalah service yang disediakan untuk membangun aplikasi yang berbasis SMS gateway. Selain mudah, aplikasi SMS gateway dengan gammu adalah free. Ada dua 
mekanisme kerja dari gammu yaitu sebagai aplikasi dan sebagai deamon. Gammu sebagai aplikasi akan bekerja ketika perintah gammu dijalankan pada lingkungan shell beserta perintahnya disertakan sesuai fungsi yang diinginkan. Sedangkan sebagai deamon, gammu ditandai dengan dijalankannya perintah smsd pada shell. Pada prinsipnya cara kerja gammu yaitu menghubungkan modem/ponsel dengan PC. SMS yang diterima di modem / ponsel akan diambil oleh gammu untuk dipindahkan ke dalam database yang telah diatur sebelumnya. (Jumri, 2012).

\section{Konsep Dasar Sistem Informasi}

1. Pengertian Sistem Informasi

Sistem adalah sekumpulan elemen yang dalam sebuah jaringan yang bekerja secara teraturdalam satu kesatuan yang bulat dan terpadu untuk mencapai sebuah tujuan atau sasaran tertentu.

2. Pengertian Informasi

Informasi merupakan sebuah hasil dari sebuah pengolahan data yang melalui sekumpulan proses pada sebuah sistem, yang diolah sedemikian rupa sehingga layak untuk disajikan kepada masyarakat umum Jenisjenis informasi dapat dipandang dari 3 segi yaitu manajerial, sumber dan rutinitasnya.

3. Pengertian Sistem Informasi

Sistem informasi adalah kumpulan atau sususnan yang terdiri dari perangkat keras dan perangkat lunak serta tenaga pelaksananya yang bekerja dalam sebuah proses berurutan dan secara bersama-sama saling mendukung untuk menghasilkan suatu produk. (Dengen, dkk, 2009).

\section{Metode}

Untuk metode penelitian Waterfall Model adalah sebuah metode pengembangan software yang bersifat sekuensial dan terdiri dari 6 tahap yang saling terkait dan mempengaruhi seperti terlihat pada gambar berikut (Hariyadi, 2010) :

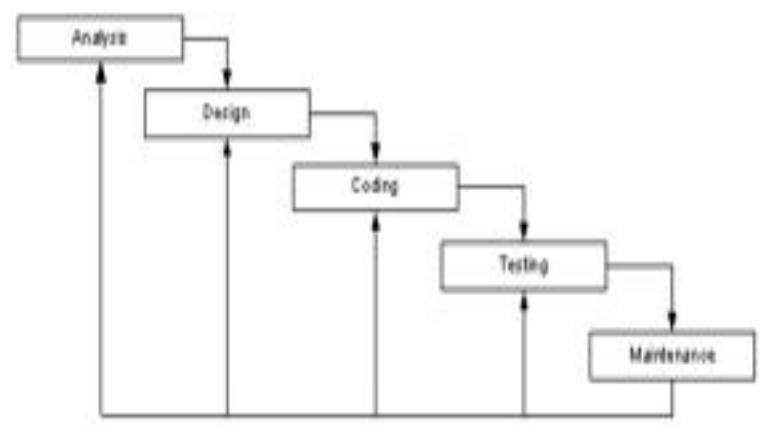

Gambar 2. Gambar Pemodelan
Berikut adalah penjelasan dari tahap-tahap yang dilakukan di dalam model tersebut:

Tahapan Analisa Kebutuhan Berikut adalah penjelasan dari tahap-tahap yang dilakukan di dalam model tersebut:

1. Tahapan Analisa Kebutuhan

Pada tahap analisis kebutuhan dilakukan dengan :

a. Wawancara (Interview).

Proses wawancara yaitu proses pengumpulan data dengan melakukan Tanya jawab dengan Bapak firman Iskandar selaku Staf IT terkait informasi akademik pada SMK Muhammdaiyah 1 Kepanjen pada bulan Januari 2014

b. Dokumentasi

Proses dokumentasi yaitu proses pengambilan data yang dilakukan dengan melihat data dan dokumen yang terkait dengan sistem akademik yang terdapat pada SMK Muhammadiyah

2. Tahapan Perancangan Sistem dan Aplikasi Merancang dan membangun aplikasi Sistem Informasi Akademik Siswa dengan Notifikasi SMS pada SMK Muhammadiyah 1 Kepanjen yaitu dengan merancang tampilan antar muka pengguna (use case) dan perancangan database meliputi table dan relasi antar table (relationship).

3. Coding

Tahapan ini dikerjakan setelah design dibuat, di lakukan perngcodingan agar perangkat lunak yang dibangun/dibuat bisa di eksekusi dan megetahui letak kesalahan, dalam hal ini pengcodingan menggunakan bahasa pemrograman PHP.

4. Testing

Testing atau pengujian ini akan menentukan apakah sistem ini layak untuk dioperasikan atau perlu adanya perbaikan lebih lanjut agar sesuai dengan fungsi dan tujuan yang diharapkan

5. Maintenance

Tahapan yang terakhir ini dilakukan setelah semua proses tahapan dilakukan, maintance/pemeliharaan ini berguna apabila perangkat lunak yang dibangun ada perubahan-perubahan sesuai dengan keinginan pengguna.

\section{Pemodelan system}

Use case diagaram 


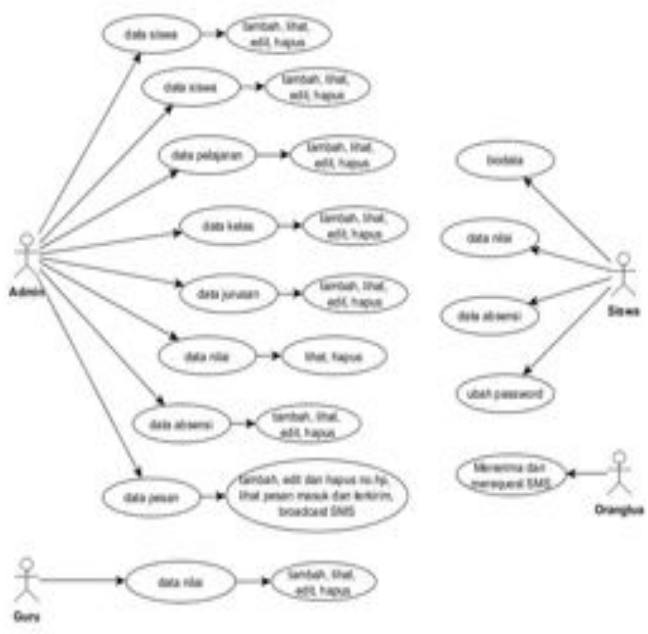

Gambar 3. Use case diagram

Pada gambar 3, usecase diagram menjelaskan peranan dan fungsi masing-masing aktor, yaitu admin, guru, siswa dan orang tua siswa. Admin harus login terlebih dahulu kemudian dapat melakukan beberapa fungsi diantaranya adalah pengelolaan data siswa, data kelas, data jurusan, data nilai, data absensi dan data pesan. Guru dapat menginputkan mengubah dan menghapus data nilai siswa. Siswa dapat melihat data diri, data nilai dan data absensi, selain itu siswa juga dapat mengubah password id nya. Sedangkan aktor orang tua siswa dapat menerima dan merequest SMS tentang absen dan nilai siswa.

\section{Flow chart diagram nilai dan absensi siswa}

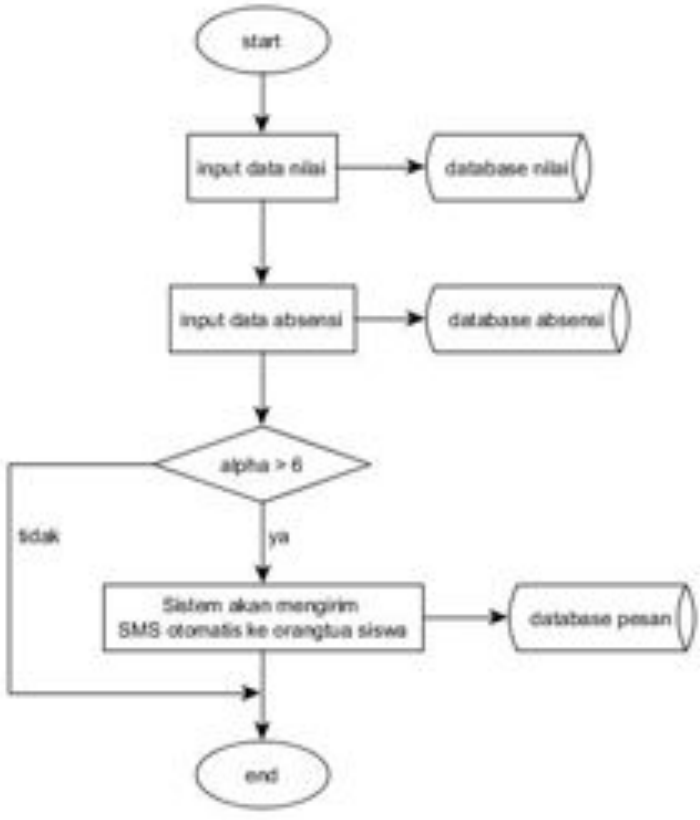

Gambar 4. Flowchart sistem
Gambar 4, mensimulasikan bagaimana sistem notifikasi SMS bekerja. Pada awalnya guru memasukan data nilai siswa dan admin memasukkan data absensi siswa, setelah data tersimpan kedalam database sistem akan membaca alpha siswa, jika lebih dari 6 alpha sistem akan otomatis mengirim SMS kepada oragtua yang siswanya melebihi batas absensi, jika tidak maka data hanya tersimpan saja dan sistem tidak akan mengirim notifikasi SMS apapun kepada orangtua siswa..

\section{Hasil}

a. Halaman yang pertama kali muncul yaitu form login untuk user, admin dan guru.

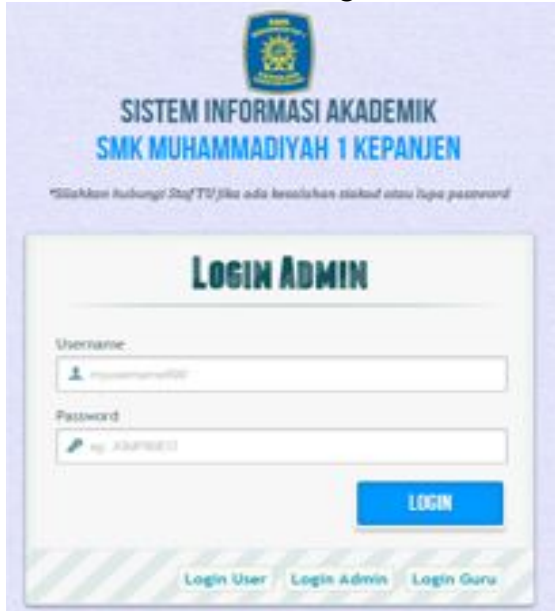

Gambar 5. Halaman utama untuk login admin

b. Halaman utama admin yaitu tentang data seluruh siswa.

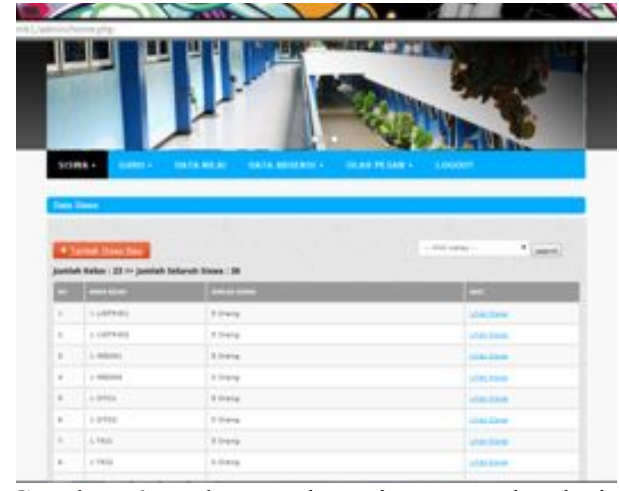

Gambar 6. Halaman data siswa untuk admin

c. Penjadwalan pelajaran yaitu digunakan untuk memasukkan pelajaran, karena pada setiap kelas semester dan tahun ajar pada sekolah mempunyai mata pelajaran yang berbeda dan guru pengajar yang berbeda pula, maka pelajaran yang di inputkan berdasarkan guru pengajar, kelas, semester dan tahun ajar. 


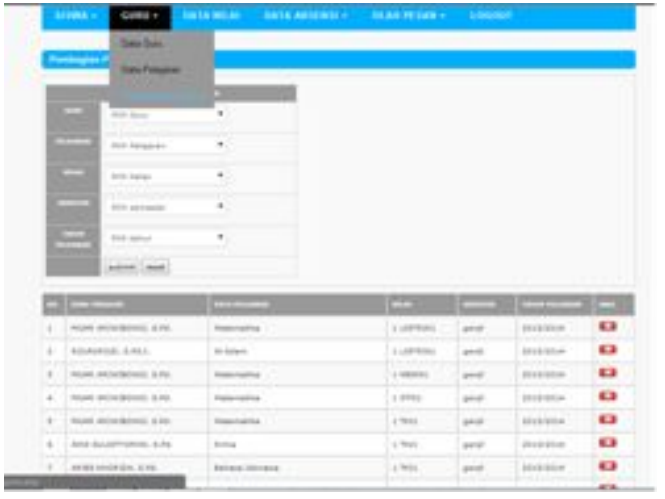

Gambar 7. Pembagian pelajaran

d. Form input nilai adalah halaman yang dapat diakses oleh guru untuk memasukkan data nilai pada mata pelajaran yang sudah dipilih. Form ini akan tampil setelah guru memlih mata pelajaran berdasarkan kelas, semester dan tahun ajar.

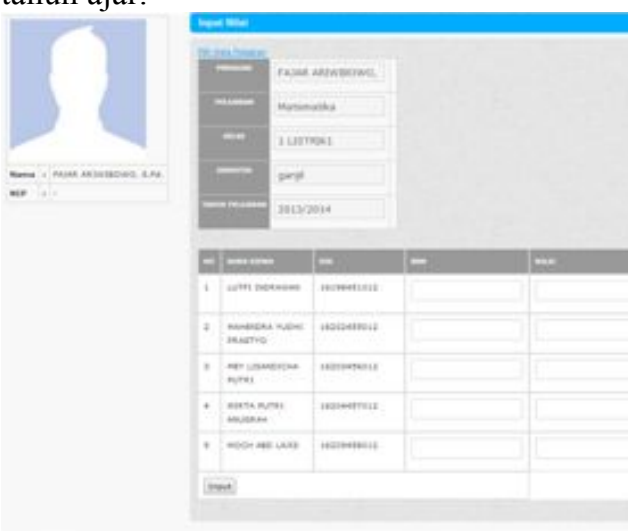

Gambar 8. Input nilai

e. Halaman ini adalah halaman yang dapat diakses oleh admin untuk menginputkan absensi siswa. Pada form input absensi admin dapat menginputkan semester, tahun ajar, tanggal dan mencentang status absensi siswa. Pada form ini pada dasarnya sama seperti form inputan nilai, admin dapat menginputkan absensi untuk seluruh siswa berdasarkan kelas yang dipilih.

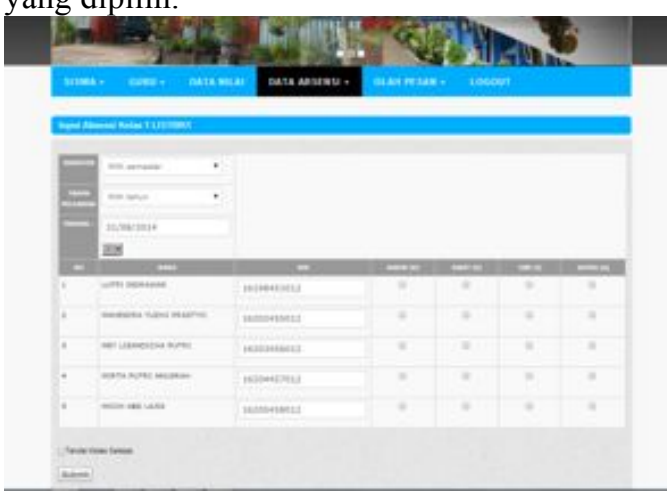

Gambar 9. Input Absensi

f. Halaman Input No.Hp

Nomor hp di inputkan berdasarkan siswa kelas dan nama orangtua, karena nantinya kelas akan di jadikan group untuk pengiriman sms masal/broadcast sms.

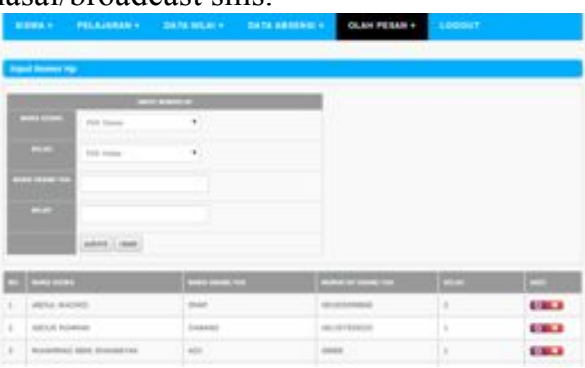

Gambar 10. Input nomor hp

g. Halaman Broadcast pesan

Pada pilihan group terdapat pilihan kelas yang nantinya jika dipilih maka akan otomatis pesan membroadcast keseluruh user pada group yang telah dipilih.

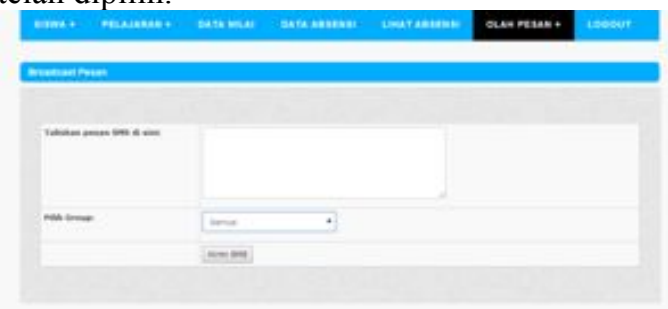

Gambar 11. Broadcast sms

h. Pesan masuk

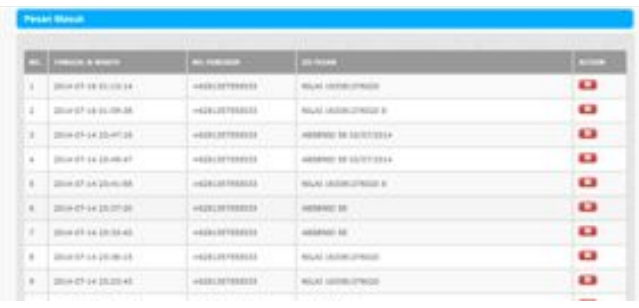

Gambar 12. Pesan masuk

i. Pesan terkirim

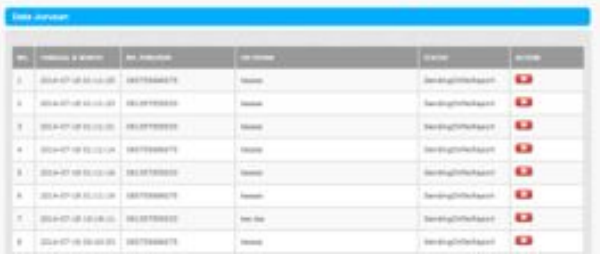

Gambar 13. Pesan terkirim

j. Hasil broadcast sms

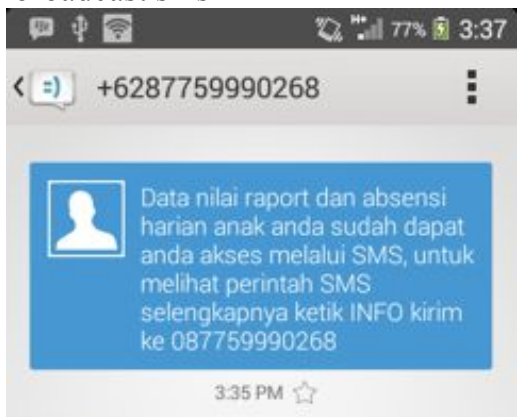

Gambar 14. Broadcast sms

k. Pada sistem notifikasi ini sms akan terkirim ke nomor orangtua siswa dengan otomatis jika siswa melebihi batas batas alpha 


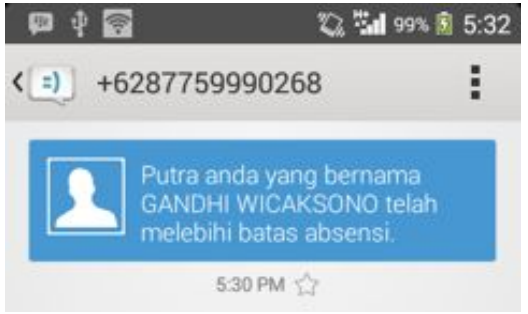

Gambar 15. SMS pemberitahuan pelanggaran

1. Auto replay dari sms permintaan orang tua siswa tentang informasi nilai dengan cara mengetikan NILAI\#NIS\#Mata pelajaran\#Tahun ajar

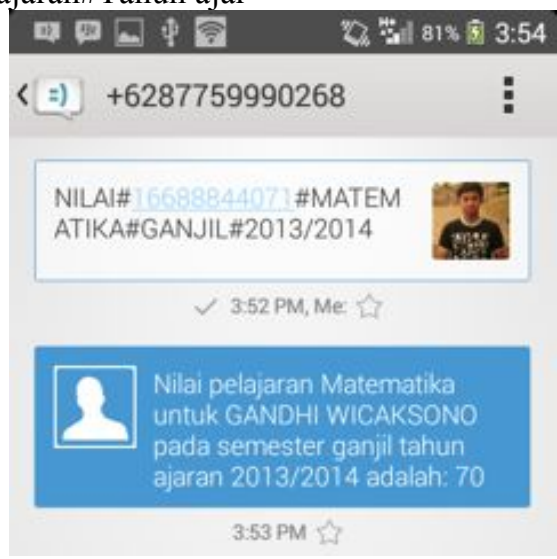

Gambar 16. Request nilai

m. Auto replay dari sms permintaan orang tua siswa tentang informasi absensi, dengan format ABSENSI\#NIS\#Tanggal

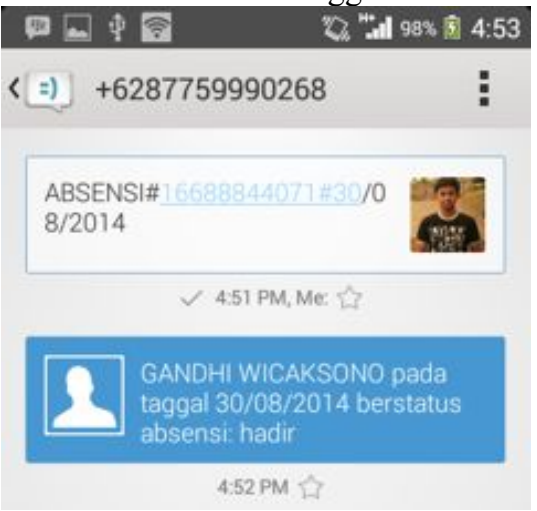

Gambar 17. Request absensi

\section{Pembahasan}

Pada sistem informasi akademik ini sebenarnya fiturnya sama seperti pada sistem informasi akademik pada umumnya, tapi yang menjadi nilai tambah adalah dibagian notifikasi SMS, bagi SMK Muhammadiyah 1 Kepanjen akan menjadi sistem yang sangat penting karena disamping menginformasikan data nilai dan absensi melalui web bagi siswanya, sistem ini juga dapat mengirim notifikasi SMS berupa pemberitahuan kepada orangtua siswa jika nilai dan absensi sudah dapat di akses, disamping itu orangtua siswa juga dapat merequest sms untuk mengetahui data nilai dan absensi putra putrinya dimanapun dan kapanpun.

\section{Kesimpulan dan Saran}

Kesimpulan:

Berdasarkan hasil analisa dan desain yang telah dilakukan dan dibahas pada bab-bab sebelumnya, maka dapat disimpulkan bahwa :

a. Dengan adanya Sistem Informasi Akademik Siswa Menggunakan Notifikasi SMS ini akan lebih memudahkan siswa mendapatkan informasi tentang nilai dan absensinya di sekolah.

b. Dengan aplikasi SMS Gateway, informasi yang dikirim akan memudahkan wali siswa mendapatkan informasi nilai maupun absensi putralputrinya kapanpun dan dimanapun.

Saran

a. Disarankan agar pihak sekolah bekerja sama dengan pihak operator celular, untuk membuat suatu sistem pembiayaan atau tarif SMS yang disamakan baik untuk user maupun nomor SMS sekolah.

b. Disarankan untuk memilih kartu GSM yang memiliki kualitas jaringan bagus agar pesan dapat sampai dengan cepat.

c. Notifikasi SMS hanya menginformasikan hasil data nilai dan absensi.

d. Sistem ini dapat dikembangkan lebih lanjut dengan fitur-fitur yang lebih baik dan lebih praktis, terutama pada bagian fitur notifikasi SMS.

\section{Daftar Rujukan}

Widharto, Yudi. (2011): "Sistem Informasi Akademik Berbasis SMS Gateway", Jurnal Teknologi Dan Informatika (Teknomatika) Volume 1 No. 1.

Jumri, Jurista Purnama. (2012): Perancangan Sistem Monitoring Konsultasi Bimbingan Akademik Mahasiswa dengan Notifikasi Realtime Berbasis SMS Gateway.

Pramono, Asep. (2010): Analisis Dan Penerapan Sms Gateway Pada "Media Info Bandara Jogja" Di Bandar Udara Internasional Adisucipto Yogyakarta

Dengen, Nataniel \& Hatta, Heliza Rahmania. (2009): "Perancangan Sistem Informasi Terpadu Pemerintah Daerah Kabupaten Paser", Jurnal Informatika Mulawarman, Volume 4, No. 
Larasati, Mifta Aulia. (2013): Raport Online Berbasis SMS Gateway dan Website Studi Kasus SMK Farmasi Yogyakarta.
Kusumadewi, Sri. 2003. Artificial Intelligence (Teknik dan Aplikasinya). Yogyakarta: Graha Ilmu 